\title{
Derivative Analysis of AVIRIS Data for Crop Stress Detection
}

Spectral derivatives and band ratios based on AVIRIS image data were used to identify nitrogen deficiency and drought stress in a Nebraska corn field. 


\title{
Derivative Analysis of AVIRIS Data for Crop Stress Detection
}

\author{
Lee Estep ${ }^{1}$, Gregory $\Lambda$. Carter ${ }^{2}$, and Judith Berglund ${ }^{3 *}$
}

${ }^{1}$ Lockheed Martin Technology Services Group, Edison, NJ, 08837-3679 USA

${ }^{2}$ Earth Science Applications Directorate, National Aeronautics and Space Administration, John C. Stennis Space Center, MS 39529 USA; Current address: Gulf Coast Research Laboratory, The University of Southern Mississippi, P.O. Box 7000, 703 East Beach Drive, Ocean Springs, MS 39564, USA

${ }^{3}$ Remote Sensing Directorate, Lockheed Martin Space Operations - Stennis Programs, John C. Stennis Space Center, MS 39529 USA[mew1]

\begin{abstract}
Low-altitude Airborne Visible/Infrared Imaging Spectrometer (AVIRIS) hyperspectral imagery of a cornfield in Nebraska was used to determine whether derivative analysis methods provided enhanced plant stress detection compared with narrow-band ratios. The field was divided into 20 plots representing 4 replicates each of 5 nitrogen $(\mathrm{N})$ fertilization treatments that ranged from 0 to $200 \mathrm{~kg} \mathrm{~N} / \mathrm{ha}$ in $50 \mathrm{~kg} / \mathrm{ha}$ increments. The imagery yielded a $3 \mathrm{~m}$ ground pixel size for 224 spectral bands.

*Corresponding author. Telephone: +1-228-688-2018; fax +1-228-688-3838; e-mail: Judith.Berglund@ssc.nasa.gov
\end{abstract}


Derivative analysis provided no advantage in stress detection compared with the performance of narrow-band ratio indices derived from the literature. This result was attributed to a high leaf area index at the time of overflight ( $\mathrm{LAI} \approx 5$ to 6 ) and the high signal-to-noise character of the narrow AVIRIS bands.

\section{Introduction}

Historically, spectroscopists have used signal derivative and ratio computations to remove background signals or noise that interferes with signals of interest (Butler and Hopkins, 1970). Similar techniques are now being used in remote sensing. For example, soil reflectance and its variability over a planted field can represent a noise source and can interfere with attempts to estimate crop parameters in agricultural remote sensing ( $\mathrm{Li}$ et al., 1993). Demetriades-Shah et al. (1990) demonstrated that derivative analysis minimized the influence of soil background in plant canopy spectra. This result was enabled by the approximately linear dependence of soil reflectance on wavelength. In contrast, vegetation spectra can be described by a cubic or higher-order polynomial. Thus, within an image pixel, the contribution of soil background is minimized in a second derivative of the spectral reflectance curve, whereas the spectral contribution from vegetation remains (Demetriades-Shah et al., 1990). Consequently, derivative analysis was superior to broadband ratio algorithms in plant stress detection. Similarly, second derivatives in the red-edge spectrum have been used to remove background noise from imagery of rangeland forage areas (Li et al., 1993). By applying derivative analysis, the 
difference between the backgrounds of burned and unburned areas was significantly reduced.

Penuelas et al. (1993) used derivatives to study spectral changes resulting from plant stress. Leaf water status and reflectance in the 950 to $970 \mathrm{~nm}$ region was assessed using derivative analysis and conventional band ratio reflectances. A Water Band Index (WBI) and the first derivative minimum over the 900 to $970 \mathrm{~nm}$ spectral regions tracked the relative water content of gerbera, pepper, and bean leaves. Penuelas et al. (1994) developed indices based on derivative analysis and narrow band ratios that proved successful in tracking diurnal changes in photosynthetic rate and seasonal changes in chlorophyll and nitrogen in sunflower leaves. Adams et al. (1999) used derivative analysis to derive a Yellowness Index (YI) for plant chlorosis detection. The YI is a three-point approximation of the second spectral derivative using a finite divided difference method and reflectances at 580, 624 , and $668 \mathrm{~nm}$.

The computation of a derivative spectrum is not difficult. Dividing the difference in reflectance between successive wavebands by the corresponding wavelength interval yields the approximate derivative spectrum. By repetition of this procedure, higher order derivative spectra can be computed. However, derivative spectra are highly sensitive to noise. Thus, smoothing must generally be done prior to derivative computation. Tsai and Philpot (1998) used the methods of Savitzky-Golay (1964) and Kawata-Minami (1984), along with a mean filter to smooth spectra prior to derivative analysis. Tsai and Philpot suggested that when the spectral features of interest are relatively broad and noise occurs at relatively high frequencies, there is little difference in results from the three methods. 
Adams et al. (1999) proposed that there is no reason why higher order derivatives cannot be taken using points farther away from the central wavelength to provide an integrated measure of spectral slope change. I Ising the finite divided difference in this manner affects a smoothing that diminishes high frequency noise between the points used to compute the derivative (Tsai and Philpot, 1998).

The objective of the present study was to use Airborne Visible/Infrared Imaging Spectrometer (AVIRIS) hyperspectral imagery to determine whether high-resolution derivative analysis methods provided enhanced capability of detecting nitrogen deficiency in corn compared with simpler, narrow-band ratio approaches.

\section{Methods}

The Variable Rate (VRAT) Nitrogen (N) Application site established by the U.S. Department of Agriculture, Agricultural Research Service (USDA ARS) at Shelton, Nebraska, represented a well-studied quarter section that supported a corn crop. Four replicate blocks, each containing five treatment plots, were established along a central alleyway that ran from east to west (Figure $1 \mathrm{~b}$ ). $\mathrm{N}$ treatments, applied using anhydrous ammonia and assigned randomly within each block, ranged from 0 to $200 \mathrm{~kg} \mathrm{~N} / \mathrm{ha}$ in $50 \mathrm{~kg} \mathrm{~N} / \mathrm{ha}$ increments. All $\mathrm{N}$ treatment plots were watered by a central pivot irrigation system on a three-day period to avoid drought stress. Bare soil patches east and west of the plots provided references for the soil spectrum and for calibration of AVIRIS data to percent reflectance. At the time of overflight, some weeds had become established in the eastern soil patch. Additionally, an arcuate water-stressed region at the north-central 
margin of the field was established. This region was created by withholding irrigation as the central pivot unit passed for 3 to 4 weeks prior to sensor overflight, enabling a comparison between water and nutrient stress effects on selected reflectance indices. The $200 \mathrm{~kg} \mathrm{~N} /$ ha plots served as experimental controls for comparison with the less fertilized plots. Visually, plots that received little $(50 \mathrm{~kg} / \mathrm{ha})$ or no fertilizer could be discerned from the control plots. However, the unaided eye could not distinguish among the 100 , 150 , and $200 \mathrm{~kg} \mathrm{~N} /$ ha plots.

AVIRIS data were acquired over the VRAT field on July 22, 1999. The AVIRIS image cube consisted of $3 \mathrm{~m}$ ground sample distance pixels at 224 spectral bands per pixel. Data from several flight lines were collected and returned to the Jet Propulsion Laboratory in Pasadena, California, for georeferencing and radiometric calibration. These data were then corrected for atmospheric effects using the ATmosphere REMoval, or ATREM routine (Gao et al., 1992). The relative reflectance imagery produced by ATREM was then scaled to correspond more closely to measured in-field crop reflectance through the use of an empirical line function procedure. Ground spectral data were acquired by portable spectroradiometers (model ASD-FS, Analytical Spectral Devices, Boulder, Colorado, USA). Canopy spectra of each plot were recorded from a cherry picker elevated to approximately $5 \mathrm{~m}$ above the ground. Average spectra were obtained from repeated spectral measurements of each plot (Figure 1a).

For present purposes, the AVIRIS data were truncated to cover the 400 to $1035 \mathrm{~nm}$ range. These image data were then used to compute various derivative and ratio-based indices that were tested for their capability as indicators of $\mathrm{N}$ deficiency in corn. First and 
second derivatives were computed at 12 band locations within the 495 to $1025 \mathrm{~nm}$ range suggested by Thenkabail et al. (2000) for use in the detection of pigment and moisture variation in crop canopies (Table 1). At least three points were needed to compute the second derivative, so bands 5 and 6 as well as bands 6 and 7 were combined for the analysis. Additionally, the derivative indices of Penuelas et al. (1994) and the Yellowness Index of Adams et al. (1999) were computed as defined by the authors (Table 2). For comparison with the derivative indices, narrow-band ratio indices including the Normalized Difference Vegetation Index (NDVI), Normalized Pigments Chlorophyll Ratio Index (NPCI) (Penuelas et al., 1994), Physiological Reflectance Index (PRI) (Gamon et al., 1992), and Water Band Index (Penuelas et al., 1993) were computed.

Derivatives and derivative-based indices were compared among treatments to determine statistically significant effects at $\mathrm{p} \leq 0.01$. Using image-processing software, Regions of Interest (ROIs) were defined for each plot. Extracted ROI data were entered into a spreadsheet and a Kolmogorov-Smirnov normality test was applied. In general, extracted ROI data were not normally distributed. Therefore, a non-parametric KruskalWallis Analysis of Variance (ANOVA) (Haber and Runyon, 1977) and the Dunn Multiple Comparison test (Siegel, 1956) were employed to determine statistical differences. The Dunn test output a two-by-two pairing that quantified whether paired plots are distinguishable from one another and the controls for a given p-value. 


\section{Results and Discussion}

First derivatives of AVIRIS reflectances computed at 495, 568, 682 and 696, 982, and $1025 \mathrm{~nm}$ (Thenkabail et al.. 2000) provided separation among all $\mathrm{N}$ treatments (Table 1 ). Although $\mathrm{d} 1$ at $568 \mathrm{~nm}$ provided separation among all $\mathrm{N}$ treatments, it remained insensitive to water stress. Also, $568 \mathrm{~nm}$ was the only band at which $\mathrm{d} 2$ identified all $\mathrm{N}$ treatments and water stress (Table 1). This result was somewhat unexpected since $\mathrm{d} 2$ serves to minimize the influence of soil reflectance (Demetriades-Shah et al., 1990). Nevertheless, leaf area index was high and approaching a maximum value when the AVIRIS data were acquired in late July. Thus, it is unlikely that soil reflectance influenced canopy reflectance significantly. It is also noteworthy that while providing separation among $\mathrm{N}$ treatments, $\mathrm{d} 1$ and $\mathrm{d} 2$ at $568 \mathrm{~nm}$ exhibited opposite sensitivities to water stress. First and second derivatives at the remaining Thenkabail et al. (2000) bands were far less effective in distinguishing among the $\mathrm{N}$ treatments (Table 1).

The $\mathrm{d} 1 \mathrm{minimum}$ in the green spectrum $(\mathrm{dg})$ and $\mathrm{d} 1$ maximum near the reflectance red edge (dRE) provided treatment separation (Table 2) similar to the derivatives at the first five bands listed in Table 1. This suggests that in tandem, derivatives in the greenpeak and red-edge spectral regions might provide a method to distinguish between water and nutrient stress in corn.

These observations corroborate earlier findings that the green-peak and red-edge spectral regions are generally critical for the detection of plant stress (e.g., Schepers et al., 1996; Carter and Knapp, 2001). The d2 maximum near the red edge (ddRE) identified only the 0,50 , and $100 \mathrm{~kg} \mathrm{~N} /$ ha treatments separately from the controls (Table 2), as did 
several $\mathrm{d} 2$ listed in Table 1. A similar separation of test plot treatments was true also for the $\mathrm{d} 1$ maximum in the green spectrum $(\mathrm{dG})$, which additionally was sensitive to water stress (Figure 1c). Derivative-based, normalized difference indices represented by the EGFN (normalized difference between $\mathrm{dRE}$ and $\mathrm{dG}$ ) and the GGFN (normalized difference between $\mathrm{dG}$ and $\mathrm{dg}$ ) did not separate $\mathrm{N}$ treatments as well as derivatives per se (Table 2). Penuelas et al. (1994) found the GGFN to correlate closely with photosynthetic efficiency, but it performed poorly in the present study because dg and dG were similar in value. Likewise, the EGFN and YI yielded low ranges in value among pixels. Thus, these indices separated only the untreated and $50 \mathrm{~kg} /$ ha treatments from the controls.

A narrow-band NDVI derived from the 680 and $850 \mathrm{~nm}$ AVIRIS bands performed as well as any derivative index in the detection of $\mathrm{N}$ deficiency (Table 2). Conversely, the NPCI based on the $430 \mathrm{~nm}$ and $680 \mathrm{~nm}$ bands, which compare the relative amount of chlorophyll to the total amount of chlorophyll plus carotenoids (Penuelas et al., 1994), provided no separation of treatments. Both chlorophyll and the carotenoids absorb strongly in the 300 to $500 \mathrm{~nm}$ range, but carotenoids do not absorb strongly in the red spectrum (Margalef, 1974). Thus, although nutrient stress may yield greater leaf concentrations of carotenoids relative to chlorophyll (Young and Britton, 1990), chlorophyll concentration can be estimated by comparing leaf reflectance between these spectral regions (Penuelas et al., 1994). In an earlier analysis of the present data that did not involve reflectance-based indices, AVIRIS reflectance was most sensitive to $\mathrm{N}$ treatment at $711 \mathrm{~nm}$ (Carter and Estep, 2002). Consequently, a modified NPCI (NPCImod) derived from reflectances at $500 \mathrm{~nm}$ and $711 \mathrm{~nm}$ provided separation among 
all $\mathrm{N}$ treatments with no sensitivity to water stress (Table 2). This heightened sensitivity to $\mathrm{N}$ deficiency translated to an increased visual contrast among treatments in the NPCImod image (Figure 1d). The brighter areas in the image depict $\mathrm{N}$ deficiency, while the water stressed area is not seen.

The ratio of reflectances at $970 \mathrm{~nm}$ and $900 \mathrm{~nm}$ (WBI) separated the 0,50 , and $100 \mathrm{kgN} / \mathrm{ha}$ treatments from the controls and indicated water stress (Table 2). However, $\mathrm{d} 1$ at the $982 \mathrm{~nm}$ and $1025 \mathrm{~nm}$ bands recommended by Thenkabail et al. (2000) distinguished among all $\mathrm{N}$ treatments in addition to the water stressed area (Table 1). Penuelas et al. (1993) found that the first derivative minimum in the 900 to $970 \mathrm{~nm}$ region tracked the relative water content of leaves, as did the WBI. Although leaf water content seemed to be the primary influence on reflectance in this near-infrared region, leaf internal structure appeared to have some effect on reflectance, as noted also by others (e.g., Maas and Dunlap, 1989; Aldakheel and Danson, 1997). This influence of leaf internal structure on reflectance might be explained by a stress-induced increase in intercellular air space. If nutrient or water stress effectively increased the amount of intercellular air space in the corn leaves, the observed increase in near-infrared reflectance would be explained (Gates et al., 1965). Even so, near-infrared reflectance has received little attention as a potential indicator of nutrient deficiencies.

\section{Conclusions}

Derivative and band ratio indices derived from AVIRIS imagery acquired at $3 \mathrm{~m}$ spatial resolution over the USDA ARS VRAT site at Shelton, Nebraska, were tested for 
their capability to discriminate $\mathrm{N}$ deficiency and water stress in corn. Focusing upon recommended band sets (Thenkabail et al., 2000) and derivative-based indices (Adams et al., 1999; Penuelas et al., 1994), it was determined that the green, red edge, and nearinfrared spectra were especially important in discriminating among $\mathrm{N}$ fertilization treatments and between nutrient and water stress. Relatively simple narrow-band indices, such as an NDVI based on the $680 \mathrm{~nm}$ and $850 \mathrm{~nm}$ bands or a modified NPCI incorporating the $500 \mathrm{~nm}$ and $711 \mathrm{~nm}$ bands, performed as well as any derivative index in discriminating among all $\mathrm{N}$ treatments and in separating nutrient stress from water stress (Table 2).

A prime motivation behind the use of derivative indices is their effectiveness in minimizing the influence of soil background reflectance (Demetriades-Shah et al., 1990). In the present study, this capability was muted by high leaf area indices within the experimental plots. Nevertheless, derivative indices might also be useful in tracking spectral shifts that occur in the far red spectrum when one moves from leaf to canopy reflectances (Zhumar, 1993; Carter and Estep, 2002). These displacements in spectral absorption features arise because of multiple radiation transfer among canopy leaves, which serve to enhance absorption and move the red edge position toward longer wavelengths in the far-red portion of the spectrum.

\section{Acknowledgments}

This research was funded by NASA's Earth Observations Commercial Applications Hyperspectral Program under the Earth Science Applications Directorate. It resulted from 
collaborative efforts among the USDA Agricultural Research Service - Beltsville, Maryland; the Boeing Company; Battelle Pacific Northwest Research Laboratory; the University of California, Santa Barbara; and Marconi. Participation by Lockheed Martin Space Operations - Stennis Programs was supported by the NASA Earth Science Applications Directorate under contract number NAS 13-650 at the John C. Stennis Space Center, Mississippi. The authors thank Marcia Wise for editing the manuscript.

\section{References}

Adams, M.L., W.D. Philpot, and W.A. Norvell, 1999. Yellowness index: an application of spectral second derivatives to estimate chlorosis of leaves on stressed vegetation, International Journal of Remote Sensing, 20:3663-3675.

Aldakheel, Y., and F. Danson, 1997. Spectral reflectance of dehydrating leaves: measurements and modelling, International Journal of Remote Sensing, 18:36833690.

Butler, W., and D. Hopkins, 1970. Higher derivatives analysis of complex absorption spectra, Photochemical and Photobiological Sciences, 12:439-450.

Carter, G.A., and L. Estep, 2002. General spectral characteristics of leaf reflectance responses to plant stress and their manifestation at the landscape scale, From Laboratory Spectroscopy to Remotely Sensed Spectra of Terrestrial Ecosystems (R. Muttiah, editor), Kluwer Academic Publishers, in press.

Carter, G.A., and A.K. Knapp, 2001. Leaf optical propertics in higher plants: linking spectral characteristics to stress and chlorophyll concentration, American Journal of Botany, 88:677-684. 
Demetriades-Shah, T.H., M.D. Steven, and J.A. Clark, 1990. High resolution derivative spectra in remote sensing, Remote Sensing of Environment, 33:55-64.

Gamon, J.A., J. Penuelas, and C.B. Field, 1992. A narrow-waveband spectral index that tracks diurnal changes in photosynthetic efficiency, Remote Sensing of Environment, $41: 35-44$

Gao, B.C., K.B. Heidebrecht, and A.F.H. Goetz, 1992. Atmospheric Removal Program (ATREM) User's Guide, Version 1.1, Center for the Study of Earth from Space Document, University of Colorado, 24 pp.

Gates, D.M., H.J. Keegan, J.C. Schleter, and V.R. Weidner, 1965. Spectral properties of plants, Applied Optics, 4:11-20.

Haber, A., and R. Runyon, 1977. General Statistics. Addison-Wesley, Reading, MA.

Kawata, S., and S. Minami, 1984. Adaptive smoothing of spectroscopic data by a linear mean-square estimation, Spectroscopy, 38:49-58.

Li, Y., T. Demetriades-Shah, E. Kanemasu, J. Shultis, and M. Kirkham, 1993. Use of second derivatives of canopy reflectance for monitoring prairie vegetation over different soil backgrounds, Remote Sensing of Environment, 44:81-87.

Maas, S., and J. Dunlap, 1989. Reflectance, absorption, and transmittance of light by normal, etiolated, and albino com leaves, Agronomy Journal, 81:105-110.

Margalef, R., 1974. Ecologia, Omega Publishing, Barcelona, Spain.

Penuelas, J., I. Filella, C. Biel, L. Serrano, and R. Save, 1993. The reflectance at the 950$970 \mathrm{~nm}$ region as an indication of plant water status, International Journal of Remote Sensing, 14:1887-1905. 
Penuelas, J., J. Gamon, A. Fredeen, J. Merino, and C. Field, 1994. Reflectance indices associated with physiological changes in nitrogen- and water-limited sunflower leaves, Remote Sensing of Environment, 48:135-146.

Savitzky, A., and M. Golay, 1964. Smoothing and differentiation of data by simplified least squares procedures, Analytical Chemistry, 36:1627-1639.

Schepers, J., T. Blackmer, W. Wilhelm, and M. Resende, 1996. Transmittance and reflectance measurements of corn leaves from plants with different nitrogen and water supply, Journal of Plant Physiology, 148:523-529.

Siegel, S., 1956. Non-parametric Statistics, McGraw-Hill, New York.

Thenkabail, P., R. Smith, and E. De Pauw, 2000. Hyperspectral vegetation indices and their relationships with agricultural crop characteristics, Remote Sensing of Environment, 71:158-182.

Tsai, F., and W. Philpot, 1998. Derivative analysis of hyperspectral data, Remote Sensing of Environment, 66:41-51.

Young, A., and G. Britton, 1990. Carotenoids and stress, Stress Responses in Plants: Adaptation and Acclimation Mechanisms (R. Hobbs and H. Mooney, editors), Springer-Verlag, New York.

Zhumar, A., 1993. Effects of vegetation cover parameters of the location of the maximum slope of the red edge, Soviet Journal of Remote Sensing, 10:594-603. 


\section{Table and Figure Captions}

\section{Table 1}

Separability of $\mathrm{N}$ treatments resulting from statistical analysis of AVIRIS image data ${ }^{\mathrm{a}}$.

Table 2

Separation of $\mathrm{N}$ fertilization treatments in corn by selected reflectance-derivative and narrow-band ratio indices derived from AVIRIS imagery ${ }^{\mathrm{a}}$.

\section{Figure 1}

(a) Soil spectrum vice spectra of untreated and control plots, (b) USDA ARS VRAT field with test plots and water stress area, (c) dG image, and (d) modified NPCI result. 
Table 1

\begin{tabular}{|c|c|c|c|}
\hline $\begin{array}{l}\text { Band Center } \\
\qquad(\mathrm{nm})\end{array}$ & $\begin{array}{l}\text { Bandwidth } \\
\qquad(\mathrm{nm})\end{array}$ & $\begin{array}{l}\text { N Treatment Separation } \\
\text { by } \mathrm{d} l\end{array}$ & $\begin{array}{c}\text { N Treatment Separation } \\
\text { by d } 2\end{array}$ \\
\hline 568 & 10 & $0,50,100,150$ & $0,50,100,150, \mathrm{~W}$ \\
\hline 495 & 30 & $0,50,100,150, W$ & $0,50,100$ \\
\hline 682 and 696 & 4 and 4 & $0,50,100,150, W$ & $0,50,100$ \\
\hline 982 & 30 & $0,50,100,150, W$ & $0,50,100, W$ \\
\hline 1025 & 10 & $0,50,100,150, W$ & $0, \mathrm{~W}$ \\
\hline 550 & 20 & $0,50,100$ & $0,50,100$ \\
\hline 525 & 20 & $0,50,100, W$ & $0,50,100$ \\
\hline 668 and 682 & 4 and 4 & $0,50,100, W$ & $0,50,100$ \\
\hline 720 & 10 & $0,50,100, W$ & $0,50,150, W$ \\
\hline 920 & 20 & $0,50,100, W$ & none \\
\hline 845 & 70 & $0,50,150, W$ & W \\
\hline
\end{tabular}

${ }^{\mathrm{a}}$ Capabilities of spectral reflectance curve derivatives to separate $\mathrm{N}$ treatments at $\mathrm{p}<0.0001$ (detection of water stress indicated by W). Cases where nutrient stress was detected but water stress was not suggest that the tested algorithm is capable of discerning between nutrient and water stress in corn. 
Table 2

\begin{tabular}{lll}
\hline \multicolumn{1}{c}{ Index } & \multicolumn{1}{c}{ Definition } & N Treatments Separated \\
\hline Derivative & & \\
$\mathrm{dg}$ & $\mathrm{d} 1$ minimum, green & $0,50,100,150$ \\
$\mathrm{dRE}$ & $\mathrm{d} 1$ maximum, red edge & $0,50,100,150, \mathrm{~W}$ \\
$\mathrm{ddRE}$ & $\mathrm{d} 2$ maximum, red edge & $0,50,100$ \\
$\mathrm{dG}$ & $\mathrm{d} 1$ maximum, green & $0,50,100, \mathrm{~W}$ \\
EGFN & $(\mathrm{dRE}-\mathrm{dG}) /(\mathrm{dRE}+\mathrm{dG})$ & 0,50 \\
YI & $\mathrm{d} 2$ & 0,50 \\
GGFN & $(\mathrm{dG}-\mathrm{dg}) /(\mathrm{dG}+\mathrm{dg})$ & none
\end{tabular}

Reflectance Ratio

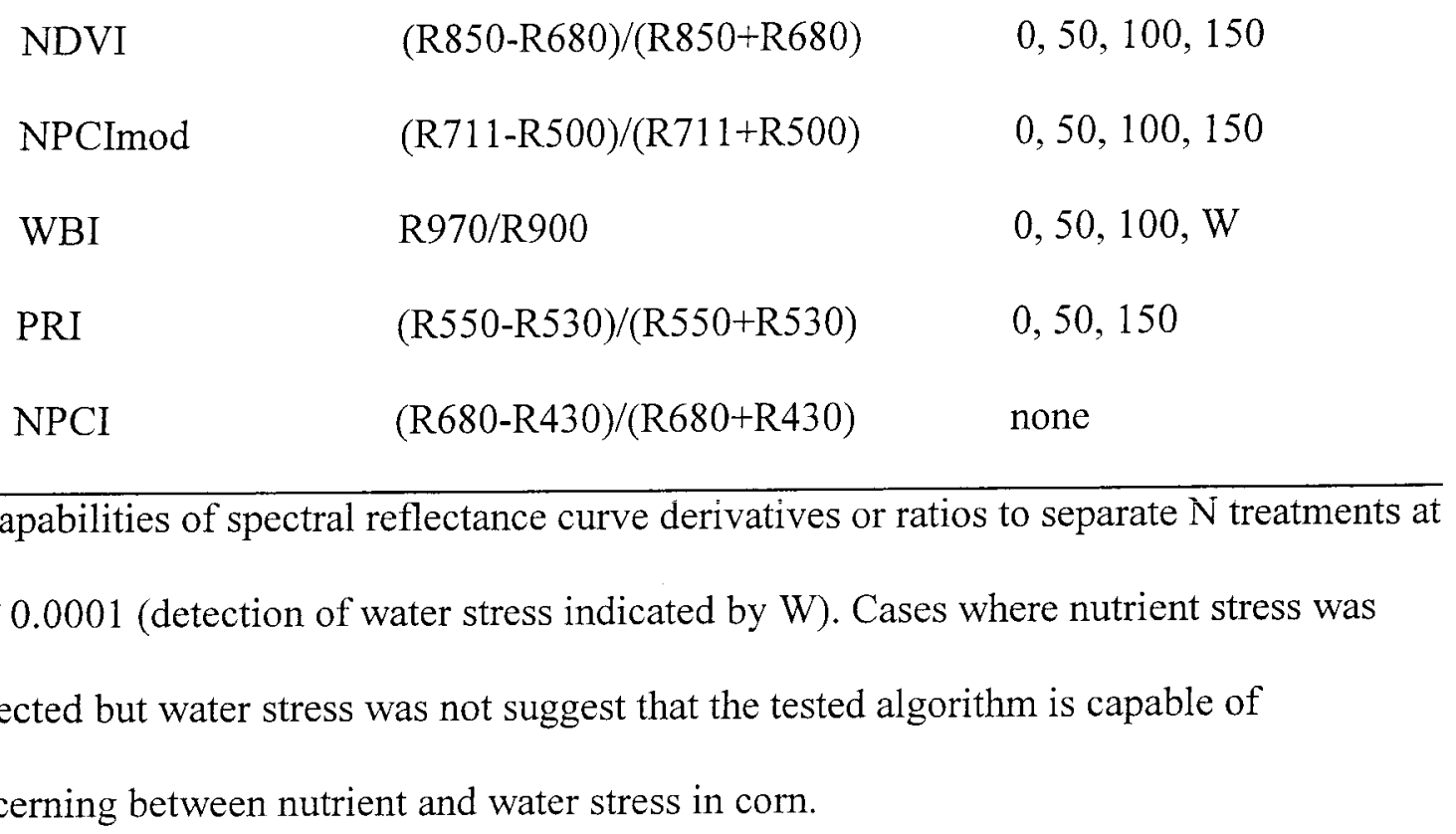


Figure 1

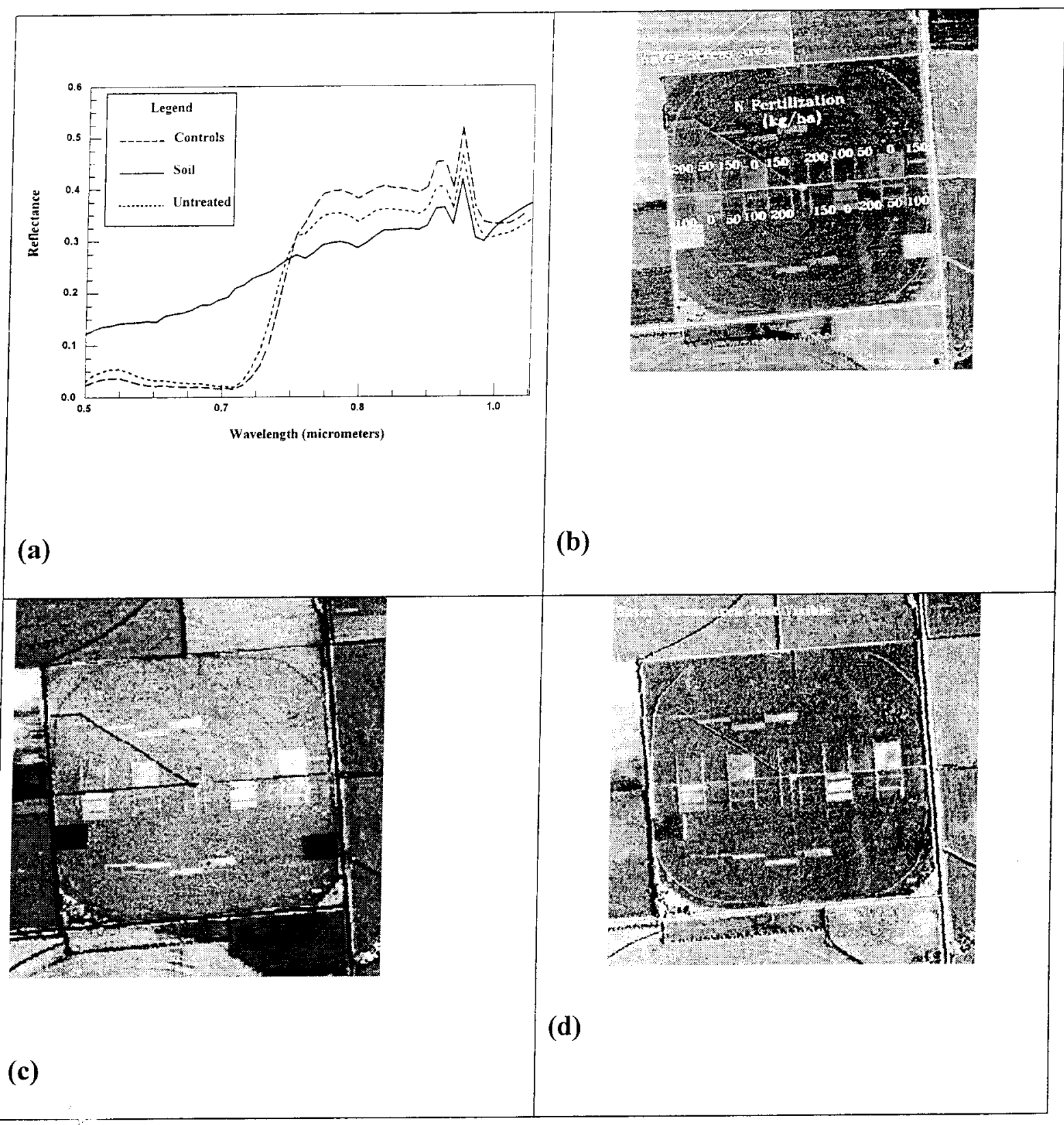

